\title{
Brote de rabia humana transmitida por gato en el municipio de Santander de Quilichao, Colombia, 2008
}

\section{An outbreak of human rabies transmitted by a cat in the town of Santander de Quilichao, Colombia, 2008}

Andrés Paez ${ }^{1}$, Luis Polo ${ }^{1}$, Damaris Heredia, Constanza Nuñez ${ }^{2}$, Milena Rodriguez,

Carlos Agudelo ${ }^{1}$, Edgar Parra $^{1}$, Andrea Paredes ${ }^{1}$, Teresa Moreno ${ }^{1}$ y Gloria Rey ${ }^{1}$

1 Laboratorio de Virología, Laboratorio de Patología, Subdirección de Vigilancia y Control en Salud Pública. Instituto Nacional de Salud. Bogotá, Colombia. apaezm@ins.gov.co

2 Laboratorio de Virilogía. Universidad del Valle. Cali, Colombia. colenume@yahoo.com

Recibido 9 Septiembre 2009/Enviado para Modificación 1 Octubre 2009/Aceptado 15 Octubre 2009

\section{RESUMEN}

Objetivos En marzo de 2008 ocurrió en el municipio de Santander de QuilichaoCauca, Colombia, un brote de rabia de origen silvestre con 2 víctimas humanas. El presente artículo apunta a describir las técnicas diagnósticas de laboratorio, las acciones de investigación de campo y control de foco empleadas, y su significado epidemiológico e implicaciones en salud pública.

Métodos La rabia se diagnosticó por inmunofluorescencia directa, prueba biológica en ratón, histopatología e inmunohistoquímica, y se tipificó utilizando anticuerpos monoclonales. La investigación de campo se enfocó en la búsqueda de contactos humanos y animales, identificación de casos sospechosos y búsqueda institucional de accidentes rábicos. El control de foco consistió en aplicación de tratamiento post exposición a la población expuesta, vacunación canina y felina, recolección y eliminación de animales callejeros y educación a la comunidad.

Resultados Dos casos de rabia en humanos fueron diagnosticados y uno en gato por nexo epidemiológico. La variante antigénica 3 fue aislada de los casos humanos. Se vacunaron en total 11369 caninos, 3325 felinos y 217 humanos.

Conclusiones Se confirma la amenaza para los humanos que representa la rabia en el ecosistema silvestre. El brote tuvo origen en vampiro y el transmisor a los humanos fue un gato confirmando a esta especie doméstica como vínculo entre la rabia de origen silvestre y el ecosistema urbano, por ende su importancia en el enfoque de las acciones de prevención y control de la rabia. Se resalta la necesidad de implementar y mantener acciones para el control de la rabia silvestre que permitan minimizar su impacto en humanos.

Palabras Clave: Rabia, Lyssavirus, Virología, Epidemiología, Zoonosis, Colombia (fuente: DeCS, BIREME).

\section{ABSTRACT}

Objectives A sylvatic rabies outbreak during March 2008 caused two human deaths in the town of Santander de Quilichao in Cauca, Colombia. This article describes the 
diagnostic laboratory techniques used, the field investigation and focus control used, as well as this outbreak's epidemiological significance and implications for public health.

Methods Rabies was diagnosed by direct immunofluorescence, biological tests involving inoculating mice, histopathology and immunohistochemistry and then typed by using monoclonal antibodies. Field investigation focused on searching for human and animal contacts, identifying suspicious cases and conducting an institutional search for rabid accidents. Focus control consisted of post-exposure treatment of the exposed population, vaccinating dogs and cats, collecting and eliminating stray animals and educating the community.

Results Two human rabies cases were confirmed in the laboratory and another was inferred in a cat by epidemiological nexus. Antigenic variant 3 was isolated from the human cases. 11,369 dogs, 3,325 cats and 217 humans were vaccinated.

Conclusions This study confirmed that rabies in the wild represents a threat for humans. The outbreak described here originated in vampire bats and was transmitted to humans by a cat, pointing out the nexus between wild rabies and the urban ecosystem which cats represent, thereby becoming a target for rabies' control and prevention activities. This study underlines the urgency of implementing and maintaining rabies control and prevention activities in the wild to minimise its impact on humans.

Key Words: Rabies, Lyssavirus, Virology, Epidemiology, Zoonoses, Colombia. (source: DeCS, BIREME).

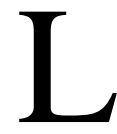

a rabia es una zoonosis terminal causada por virus neurotrópicos del género Lyssavirus (1) que ocurre en dos formas epidemiológicas a. La urbana con el perro como principal reservorio y transmisor y; b. La silvestre con animales como los murciélagos, zorros y lobos como reservorios y transmisores, y los gatos como transmisores. Eventualmente ocurre la transmisión entre estas dos formas (2-9), resaltando el riesgo para los humanos que representa la enfermedad en cualquier especie animal. La rabia es endémica en casi toda Latinoamérica; en Colombia, la forma urbana se ha encontrado limitada a brotes durante los últimos años al departamento de Magdalena y la forma silvestre ocurre de forma esporádica en la mayor parte del territorio. De esta última su principal reservorio y transmisor a especies ganaderas y humanos es el vampiro hematófago Desmodus rotundus. Otras especies de quirópteros especialmente de hábitos insectívoros son reservorios y transmisores de rabia silvestre, pero su impacto en salud pública ha sido de escasa magnitud. La población colombiana se ha visto afectada históricamente por brotes urbanos de la enfermedad (1013), sin embargo, en los últimos años la rabia silvestre ha tomado una inesperada importancia en Colombia (14), al igual que en países como Perú y Brasil por el incremento de casos en humanos de comprobado origen silvestre (15-19). En el mes de marzo de 2008 se registraron dos casos de rabia humana de origen silvestre en estudiantes que tuvieron contacto con un gato en un colegio del 
municipio de Santander de Quilichao, departamento del Cauca. Este artículo describe en detalle esta situación caracterizada como un brote de rabia humana, las técnicas diagnósticas, las acciones de investigación de campo y control de foco utilizadas y su impacto.

\section{MATERIALES Y MÉTODOS}

Diagnóstico y tipificación antigénica del virus de la rabia

Se realizó mediante la técnica de inmunofluorescencia directa (IFD) $(20,21)$ e histopatología o inmunohistoquímica sobre material encefálico (22) y prueba biológica en ratones cepa Institute Cancer Research (ICR) (23). La tipificación viral se efectuó por inmunofluorescencia indirecta (IFI) utilizando anticuerpos monoclonales (24).

Localización y descripción geográfica de las zonas de riesgo

Se efectuaron visitas e inspecciones a la zona donde ocurrieron los casos de rabia humana y animal. Las visitas tuvieron dos objetivos principales: primero, la investigación de campo y estudio epidemiológico por medio de la descripción de las áreas y comunidades afectadas por la transmisión del virus de la rabia y la toma de testimonios de amigos y familiares de las víctimas humanas. Segundo, el control de foco por medio de la vacunación de animales y humanos que hubiesen tenido contacto con casos positivos y las estrategias de información y educación a la comunidad (IEC).

Investigación de campo

La investigación de campo tuvo como objetivo principal detectar probables casos de rabia humana o de exposiciones rábicas para ser intervenidas oportunamente por medio de las acciones de control de foco. Las actividades específicas se dividieron en cuatro: a. Configuración y seguimiento de casos en humanos mediante la recolección de los testimonios de las personas expuestas, sus familiares y el seguimiento clínico de las mismas. Para esto se revisaron las historias clínicas de los pacientes evaluando las variables más importantes para caracterizar los casos como son la edad, ubicación anatómica de la mordedura, grado de la exposición, síntomas, tipo de atención brindada, fecha de inicio de síntomas y fecha de muerte, entre otros. b. Búsqueda activa de casos y contactos humanos basada en las definiciones de caso establecidas en el protocolo de rabia del Ministerio de la Protección Social y el Instituto Nacional de Salud de Colombia (25). Se aplicaron encuestas para investigar el riesgo de exposición a los compañeros de colegio de las víctimas, a los familiares y amigos de los casos probables y a los contactos hospitalarios correspondientes al personal de salud que atendió los casos. Aunque 
nunca se ha reportado la transmisión de rabia de humano a humano existe el riesgo potencial de que esta pueda presentarse, por lo cual se amplió la definición de exposición grave a aquellas personas (familiares o trabajadores de salud) que tuvieron contacto de piel lesionada o mucosas (oral o conjuntival) con fluidos corporales o tejido (saliva, lagrimas, liquido cefalorraquídeo o tejido neurológico) provenientes de los humanos infectados o presuntamente infectados con el virus de la rabia. c. Búsqueda activa de casos sospechosos de rabia en perros y gatos en el área urbana, así como bovinos, porcinos, equinos, ovinos y caprinos en todo el municipio. Se localizaron cuevas de murciélagos tanto en las zonas urbanas como en las rurales evaluando sintomatología de riesgo en estos animales. Se enviaron muestras para diagnóstico al Instituto Nacional de Salud (INS), Instituto Colombiano Agropecuario (ICA) y Universidad del Valle. d. Búsqueda activa de accidentes rábicos ocurridos entre el 15 de febrero (día de exposición de los menores) y el 27 de marzo (día de inicio del brote) a través de la revisión de historias clínicas en la institución de atención de segundo nivel del municipio en donde consultaron inicialmente los casos confirmados.

Control de foco

El objetivo principal del control de foco fue detener la circulación viral en la zona. Las actividades de campo desarrolladas requirieron la delimitación de las áreas de riesgo, para lo cual se estableció un área de foco de un kilómetro a la redonda del caso índice para el control de la rabia en el ecosistema urbano, y se utilizó la metodología de círculos concéntricos para el control de la rabia en el ecosistema silvestre. Dicha metodología consiste en demarcar una primera área de vigilancia focal circular de un kilómetro, una segunda de cinco kilómetros y una tercera de diez kilómetros (26). En la primera y segunda área se realiza búsqueda activa de casos sospechosos en animales de producción y en la tercera área se indaga acerca de mordeduras recientes por murciélagos en estas especies. El control de foco se dividió en cinco actividades específicas: a) Aplicación de tratamiento post exposición a la población expuesta: Se suministraron tratamientos de vacunación anti-rábica post exposición a las personas que sufrieron agresiones por animales potencialmente transmisores de rabia y a las que estuvieron en contacto con los humanos diagnosticados como positivos. Dichos tratamientos consistieron en cinco dosis aplicadas a los $0,3,7,14$ y 30 días en el músculo deltoides en los casos de exposición leve y adicionalmente la aplicación de suero anti-rábico en los casos de exposición grave, según protocolo y guía de atención a pacientes agredidos por animal potencialmente transmisor de rabia (26). La vacuna antirrábica utilizada fue producida en células Vero y el suero heterólogo de origen equino. b) Vacunación canina y felina: Se realizó casa a casa en la zona urbana y por concentración en la zona rural del municipio de Santander de 
Quilichao utilizando difusión de la actividad por perifoneo y otros medios de comunicación. La vacuna se aplicó a animales mayores de dos meses vía subcutánea en la región interescapular o cruz, utilizando vacuna en cerebro de ratón lactante. c) Recolección y sacrificio de perros y gatos callejeros: La cual se realizó con la colaboración del Centro de Zoonosis de Cali durante cuatro días. El sacrificio se efectuó mediante inoculación de una dosis de fenilhidantoína y pentobarbital sódico en la vena cefálica respetando los lineamientos del Estatuto Nacional de protección animal consagrado en la ley 84 de 1989. d) Información y educación a la comunidad: La alcaldía de Santander de Quilichao informó a la comunidad sobre el riesgo que presenta el contacto con animales callejeros y la importancia de vacunar a las mascotas para prevenir la presentación de casos de rabia. e) Acciones de control de la rabia silvestre: Las actividades de control se enfocaron a la disminución de la población de vampiros hematófagos mediante la utilización de mallas para su captura, clasificación, impregnación con pasta vampiricida y posterior liberación.

Recolección y registro electrónico de los datos

Se creó una base de datos en Microsoft Office Excel XP donde se registraron todas las variables para la clasificación del riesgo en los contactos humanos.

\section{RESULTADOS}

\section{Diagnóstico y tipificación viral}

Se confirmó rabia en dos humanos por IFD, inmunohistoquímica, histopatología y prueba biológica en ratones de laboratorio. Las muestras humanas evidenciaron encefalitis aguda linfomonocitaria, de predominio motor en el tallo, cerebelo y lóbulos temporales, edema cerebral generalizado, pérdida segmentaria en las neuronas de Purkinje, motoneuronas del tallo y en la corteza temporal; presencia de micronódulos gliales reactivos, fenómenos de satelitosis y neuronofagia. Los corpúsculos de Negri fueron abundantes a todo nivel, particularmente en el lóbulo temporal. Se aisló la variante antigénica (VA) 3 como la única presente en el tejido encefálico de los dos casos humanos.

Descripción geográfica de las zonas de riesgo

El municipio de Santander de Quilichao esta ubicado en el sur occidente de Colombia y en el nororiente del departamento del Cauca a 1071 metros sobre el nivel del mar (msnm), en los $3^{\circ} 00^{\prime} 47^{\prime \prime}$ latitud norte y $2^{\circ} 23^{\prime} 38^{\prime \prime}$ longitud oeste, con una temperatura promedio de $26^{\circ} \mathrm{C}$ (Figura 1). Su extensión es de $518 \mathrm{~km} 2$, con siete centros poblados, 104 veredas y cinco cabildos indígenas. Tiene una población 
triétnica de 80282 habitantes con una distribución porcentual equitativa entre las áreas urbana y rural, constituida por 47,2 \% de mestizos, $33,4 \%$ de afro descendientes y 19,4\% de indígenas, de la etnia Páez en su mayoría. La economía está basada en ganadería extensiva y agricultura con cultivos como café, caña de azúcar y piña.

Figura 1. Ubicación geográfica de la zona del brote y zonas vecinas

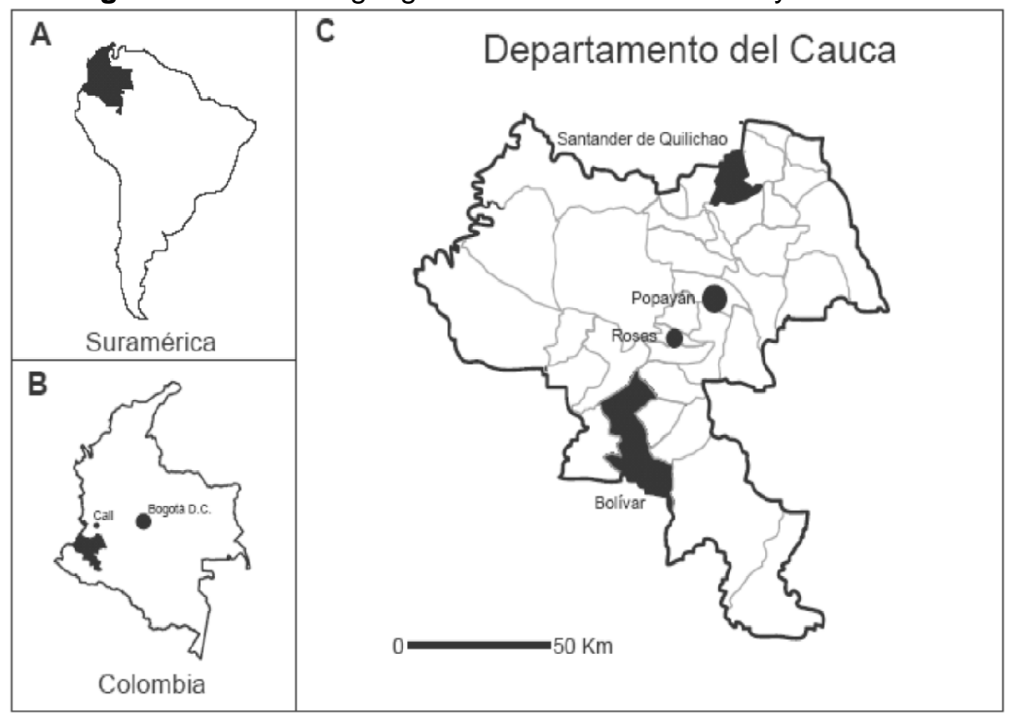

A) Mapa de Suramérica y la ubicación geográfica de Colombia. B) Mapa de Colombia con la ubicación geográfica del departamento del Cauca y la ciudad de Cali. C) Mapa del departamento del Cauca que muestra la ubicación geográfica de Popayán, ciudad capital del departamento, y de los municipios de Santander de Quilichao, Rosas y Bolívar.

Investigación de campo

Configuración y seguimiento de casos en humanos. El caso uno fue un paciente masculino de 12 años quien sufrió agresión en el quinto dedo de la mano derecha por un gato el 15 de febrero de 2008 durante el tiempo de estancia en su colegio. Los síntomas iniciaron el 15 de marzo con dolor en el miembro superior derecho y fiebre. Posteriormente osteomialgias, cefalea, dolor con disminución de fuerza en miembros superiores, vómito persistente, debilidad muscular generalizada, sialorrea, cianosis, dificultad respiratoria, convulsiones tonicoclónicas en miembros inferiores, paro cardiorespiratorio, y muerte cerebral. El paciente fallece el 27 de marzo. El caso dos fue un paciente masculino de 10 años quien mientras estaba en su colegio sufrió agresión en el primer dedo de ambas manos el 15 de febrero de 2008 por el mismo gato causante del caso uno. Los síntomas 
iniciaron el 21 de marzo con odinofagia, dolor en el hemicuello, fiebre, adenopatías cervicales dolorosas y amígdalas hipertróficas supurativas. Posteriormente dificultad para hablar, anestesia en miembro superior izquierdo sin tono muscular, desviación de la cabeza hacia la derecha, sensación de ahogo y náusea al tomar agua, finalmente cianosis, convulsiones y dificultad respiratoria. El paciente fallece el 4 de abril.

Búsqueda activa de casos y contactos humanos. Se encontraron 204 estudiantes que tuvieron posible contacto con el gato en el colegio. Las edades de estos estudiantes estuvo en un rango de 10 a 16 años distribuidos así: el 42,1\% tenían 11 años, 23,7 \% 12 años, 22,6 \% 10 años, 5,8 \% 13 años, 4,2 \% 14 años, $0,5 \% 15$ años y $1 \% 16$ años. De los 204 contactos, 11 fueron exposiciones graves $(5,3 \%)$ y 66 fueron exposiciones leves $(32,3 \%)$, los restantes 127 casos fueron clasificados como no exposiciones $(62,3 \%)$. Se clasificaron ocho casos como probables (incluyendo los dos casos humanos confirmados) por presentar síntomas compatibles con rabia y referir contacto directo con el gato infectado o con los casos humanos confirmados. Se encontraron 150 contactos familiares de los ocho casos probables y 84 contactos hospitalarios; De estos 234 contactos 57 fueron clasificados como exposiciones graves, 83 como exposiciones leves y 94 como no exposiciones.

Búsqueda activa de casos sospechosos de rabia en animales. No fue posible encontrar evidencia física del animal causante de las agresiones sucedidas en el colegio y se infiere como un caso positivo de rabia animal por el nexo epidemiológico con los casos humanos positivos para rabia. Se encontraron siete animales muertos (un perro y seis gatos) y dos animales enfermos (un gato y un perro). Se recorrieron 48 de las 59 veredas del municipio y visitaron 331 predios donde evaluaron 2711 bovinos, 855 porcinos, 541 equinos y 62 animales entre ovinos y caprinos, encontrando un equino con sintomatología nerviosa y otro muerto. En el área urbana se capturaron dos murciélagos que fueron clasificados como insectívoros del género Saccopteryx. En el área rural de mayor incidencia de mordeduras se encontraron tres refugios donde se capturaron cuatro murciélagos, sin evidenciar la presencia de vampiros; Las muestras de los siete gatos, dos perros, dos equinos y seis murciélagos hallados en la búsqueda activa fueron diagnosticadas por inmunofluorescencia directa como negativas para rabia.

Búsqueda activa institucional de otros accidentes rábicos. En el hospital local se revisaron 4722 registros de consulta médica realizados entre el 15 de febrero y el 27 de marzo de 2008 encontrándose 18 registros de agresiones por animales potencialmente transmisores de rabia, que fueron reclasificados y 
buscados los pacientes para aplicación de tratamiento. Adicionalmente se revisaron 164 historias clínicas con diagnóstico de heridas en general para determinar la causa de estas sin encontrarse ningún registro compatible con exposición rábica y se efectuó búsqueda activa institucional (BAI) analizando los 13261 registros individuales de prestación de servicios (RIPS) del primer trimestre de 2008, de los cuales se encontraron 3 diagnósticos de accidente rábico clasificados como no exposición.

Control de foco

Aplicación de tratamiento pos exposición a la población expuesta. Se aplicaron en total 217 esquemas de vacunación y 68 sueros anti-rábicos, asegurando un cubrimiento del $100 \%$ de los contactos.

Vacunación canina y felina. Se vacunaron 6260 caninos y 1729 felinos en zona rural; 5099 caninos y 1596 felinos en zona urbana, para un total de 11359 caninos y 3325 felinos en las viviendas visitadas entre el 3 y 11 de abril de 2008 . Las anteriores cifras corresponden a un $100 \%$ de coberturas de vacunación en caninos y felinos.

Recolección y eliminación de animales callejeros. Se recolectaron 20 gatos y 20 perros callejeros sin dueño los cuales fueron sacrificados y diagnosticados como negativos para infección por rabia. d) Educación a la comunidad: Las campañas educativas sobre los factores de riesgo para la transmisión de la rabia fueron dirigidas a padres de familia, niños del colegio municipal y comunidad en general. Se realizó capacitación y actualización en rabia al recurso humano involucrado en la prestación de servicios de salud como médicos, enfermeros, estudiantes de medicina y enfermería de instituciones de educación superior del Cauca y Valle del Cauca. De igual forma se impartieron charlas de educación y sensibilización a miembros de sociedades defensoras de animales. El plan de medios para la socialización de la situación del brote de rabia incluyó comunicados de prensa, radio, televisión, perifoneo, visitas a las viviendas, entrega de volantes y cartillas educativas. Se llevaron a cabo reuniones con líderes comunitarios y capacitaciones de promoción, prevención y control de la rabia a los Comités de Participación y Vigilancia Comunitarias. e) Acciones de control de la rabia silvestre: En dos actividades de captura de murciélagos realizadas en área rural del municipio se clasificaron 36 murciélagos como hematófagos, de estos se impregnaron cinco para el control de población y dos se enviaron al laboratorio para determinar circulación viral con un resultado negativo. 


\section{DISCUSIÓN}

El presente artículo describe un brote de rabia silvestre que cobró la vida de dos personas. A pesar de que el transmisor fue un gato, los resultados de la tipificación viral utilizando anticuerpos monoclonales demostraron que los virus aislados de ambos casos pertenecían a la VA3 la cual está asociada a murciélagos hematófagos (27). La infección por virus de la rabia ha sido ampliamente reportada en estos murciélagos los cuales han ocasionado brotes de la enfermedad en humanos, animales domésticos y de producción principalmente bovinos. Los resultados de este estudio en conjunto con reportes epidemiológicos anteriores de ausencia de variantes antigénicas diferentes a la VA3 y ausencia de rabia canina en la zona, confirman que el brote objeto de este estudio fue causado por virus cuyo reservorio son los murciélagos hematófagos. Los murciélagos hematófagos más frecuentemente asociados con rabia son los pertenecientes a la especie $D$. rotundus, los cuales están distribuidos desde el norte de México hasta el cono sur y en las islas de Trinidad y Margarita en el Océano Atlántico, en altitudes de hasta $3500 \mathrm{msnm}$. Las otras dos especies de murciélagos hematófagos corresponden a Diaemus youngi y Diphylla ecaudata aunque su importancia como reservorios y transmisores de rabia es secundaria (28). Además de la VA3, la VA5 ha sido aislada en D. rotundus en Colombia y otros países de Latino América.

La transmisión de la rabia de murciélagos hematófagos a humanos ha sido reportada durante los últimos 80 años en 9 países de Latino América (Trinidad, Guyana, México, Brasil, Bolivia, Argentina, Surinam, Belize, Perú y Colombia) $(14,29,30-34)$. En Colombia en la última década se han presentado 19 casos de transmisión directa de rabia a humanos por murciélago hematófago; 17 casos ocurridos en la selva húmedo tropical del departamento del Chocó en la costa del océano Pacífico (14), entre los años 2004 a 2005, involucrando comunidades indígenas, un caso en zona rural del municipio de San Luis de Palenque, departamento de Casanare en 2007, y otro caso en zona rural del municipio de Floridablanca, departamento de Santander en 2008 (Instituto Nacional de Salud, Bogotá D.C.). El $100 \%$ de los casos mencionados estuvo asociado a la VA3 del virus de la rabia transmitidos por murciélagos hematófagos de la especie $D$. rotundus, confirmándose 14 casos por nexo epidemiológico y cinco casos por laboratorio. El estudio morfológico del material encefálico de los 2 casos humanos descritos en este artículo reveló un especial compromiso inflamatorio en las áreas motoras del tallo y segmento medular cervical C1, acorde con los hallazgos evidenciados en otros casos de rabia humana paralítica. Los cambios por hipoxia e isquemia se relacionan con lesión de los centros reguladores de la actividad 
cardiorespiratoria en el bulbo; de igual manera se observaron hallazgos semiológicos propios de lesión en pares craneales de localización bulbar y mesencefálica. El proceso inflamatorio, particularmente en los lóbulos temporales generó episodios convulsivos. En este artículo se muestra el riesgo para los humanos que representa la rabia en el ecosistema silvestre aún en zonas de baja incidencia como es el caso del departamento del Cauca, donde además de los casos objeto de estudio, se reportaron durante 2008 solamente tres casos de rabia, los cuales ocurrieron en un humano del municipio de Bolívar (Instituto Nacional de Salud, Bogotá D.C.) y dos bovinos del municipio de Rosas (Instituto Colombiano Agropecuario, Bogotá D.C.) (Figura 1) Mas aun en los departamentos aledaños como Tolima y Huila no se registraron casos de rabia en humanos o animales durante 2008; únicamente el departamento aledaño del Valle del Cauca notificó dos casos de rabia los cuales resultaron ser de VA4 y aislados en murciélagos insectívoros (Universidad del Valle, Cali). En este estudio se resalta la gran importancia que tienerealizar una vigilancia activa sostenible para infección rábica en el ecosistema silvestre, con el fin de clasificar las zonas de mayor riesgo en Colombia. Se confirma el importante rol que presentan los gatos como transmisores de rabia desde especies silvestres hacia los humanos. El más reciente caso en Colombia de transmisión de rabia de gato a humano anterior a los descritos en este artículo se reportó en 2003, en área rural del municipio de Quipile, departamento de Cundinamarca, en el cual se identificó la VA8 asociada a zorros (35). Anteriormente, en 2000 en el área rural del municipio del Dovio, departamento del Valle del Cauca se detectó la VA3 en un gato que mordió a tres personas, donde no hubo víctimas humanas, gracias a la oportuna vacunación y tratamiento anti-rábico a los mordidos (Universidad del Valle, Cali). Posteriormente y durante la elaboración de este estudio ocurrió la muerte de una persona por rabia AV4 con antecedentes de mordedura de gato en el municipio de Moniquirá departamento de Boyacá en el mes de marzo de 2009 (Instituto Nacional de Salud, Bogotá D.C.).

Por todos estos antecedentes y por anteriores estudios de epidemiología molecular de la rabia en Colombia, se ha podido establecer que la rabia en gatos históricamente ha estado asociada con reservorios silvestres principalmente vampiros de la especie $D$. rotundus y en menor grado con murciélagos insectívoros y zorros. La rabia en gatos por lo contrario ha tenido escasa relación con la rabia canina, aun cuando ambas especies conviven en zonas urbanas. A este respecto se ha observado el papel inocuo de la población de gatos en brotes de rabia canina en zonas urbanas como fue el caso del Distrito de Santa Marta entre los años 2006 y 2008, a pesar de que se confirmó rabia en decenas de perros y transmisión a humanos, no se diagnosticó rabia en ningún gato (13). Se 
infiere la importancia de realizar campañas de vacunación masiva y de mantenimiento en las poblaciones de gatos y perros en zonas urbanas y rurales, dado el riesgo de contagio por contacto con especies silvestres reservorios y transmisores de rabia como es el caso de los quirópteros en la mayor parte de Colombia, y de zorros particularmente en los departamentos de Santander, Magdalena y Tolima (36). La coordinación de las acciones de investigación de campo y de control de foco descritas en el presente estudio fue de vital importancia para reducir el impacto de la rabia en humanos a pesar de las dificultades de carácter económico, logístico y ético que se presentan para realizar actividades de control y eliminación de la rabia en el ecosistema silvestre

Agradecimientos: Los autores del presente estudio desean agradecer al personal de la Secretaría Departamental de Salud del Cauca en especial al doctor Giovanni Apraez, Hospital San José de Popayán, Hospital Francisco de Paula Santander del municipio de Santander de Quilichao, Colegio Instituto Técnico de Santander de Quilichao, Centro de Zoonosis de Cali, Unidad Ejecutora de Saneamiento del Valle, Secretaria Departamental de Salud del Valle del Cauca y Hospital Universitario del Valle en la ciudad de Cali. Los autores también desean agradecer al personal del Instituto Colombiano Agropecuario (ICA) en especial al doctor Andrés Osejo en el Departamento del Cauca por su valiosa colaboración en las acciones de control de brote, al doctor Juan José Mena, alcalde de Santander de Quilichao y al doctor Moisés Mosquera, coordinador municipal de salud pública por el apoyo ofrecido en las actividades de campo.

\section{Conflictos de Interés: Ninguno}

\section{REFERENCIAS}

1. Beran GW, Steele JH. Handbook of Zoonoses, section B, pp 307. Boca Ratón, FI: CRC Press; 1994.

2. Bourhy H, Kissi B, Audry L, Smreczak M, Sadkowska-Todys M, Kulonen K, et al. Ecology and evolution of rabies virus in Europe. J Gen Virol. 1999; 80: 2545-57.

3. Guerra MA, Curns AT, Rupprecht CE, Hanlon CA, Krebs JW, Childs JE. Skunk and raccoon rabies in the eastern United States: temporal and spatial analysis. Emerg Infect Dis. 2003; 9: 1143-50.

4. Nel LH, Jacobs J, Jaftha J, Meredith C. Natural spillover of a distinctly Canidae-associated biotype of rabies virus into an expanded wildlife host range in southern Africa. Virus Genes. 1997; 15: 79-82.

5. Sabeta CT, Bingham J, Nel LH. Molecular epidemiology of canid rabies in Zimbabwe and South Africa. Virus Res. 2003; 91: 203-11.

6. Johnson N, Black C, Smith JS, Un H, McElhinney LM, Aylan O, et al. Rabies emergence among foxes in Turkey. J Wild Dis. 2003; 39: 262-70.

7. Krebs JW, Williams SM, Smith JS, Rupprecht CE, Childs JE. Rabies among infrequently reported mammalian carnivores in United States, 1960-2000. J Wildl Dis. 2003; 39: 253-61.

8. Stankov S. Typing of field rabies virus strains in FR Yugoslavia by limited sequence analysis and monoclonal antibodies. Med Pregl. 2001; 54: 446-52. 
9. Páez A, Saad C, Núñez C, Bóshell J. Molecular epidemiology of rabies in northern Colombia 19942003: Evidence for human and fox rabies associated with dogs. Epidemiol Infect. 2005; 133: 529-36.

10. Páez A, Núñez C, García C, Bóshell J. Molecular epidemiology of rabies epizootics in Colombia: evidence for human and dog rabies associated with bats. J Gen Virol. 2003; 84: 795-802.

11.Páez A, Núñez C, García C, Bóshell J. Epidemiología molecular de epizootias de rabia en Colombia 1994-2002. Evidencia de rabia humana y canina asociada a quirópteros. Biomédica 2003; 23 (1): 19-30.

12. Hughes GJ, Páez A, Bóshell J, Rupprecht CE. A phylogenetic reconstruction of the epidemiological history of canine rabies virus variants in Colombia. Infect Gen Evol. 2004; 4: 45-51.

13. Paez A, Rey G, Agudelo C, Dulce A, Parra E, Diaz-Granados H, Heredia D, Polo L. Brote de rabia urbana transmitida por caninos en el Distrito de Santa Marta, Colombia, 2006-2008. 2008. Biomédica 2009; 29: 424-36.

14. Valderrama J, García I, Figueroa G, Rico E, Sanabria J, Rocha N, Parra E, Saad C, Paez A. Brotes de rabia humana transmitida por vampiros en los municipios de Bajo y Alto Baudó, departamento del Chocó, Colombia 2004-2005. Biomédica 2006; 26: 387-96.

15. Lopez A, Miranda P, Tejada E, Fishbein DB. Outbreak of human rabies in the Peruvian jungle. Lancet. 1992;339 (8790):408-11.

16. Warner CK, Zaki SR, Shieh WJ, Whitfield SG, Smith JS, Orciari LA, Shaddock JH, Niezgoda M, Wright CW, Goldsmith CS, Sanderlin DW, Yager PA, Rupprecht CE. Laboratory investigation of human deaths from vampire bat rabies in Peru. Am J Trop Med Hyg. 1999;60(3):5027.

17. Gonçalves MA, Sá-Neto RJ, Brazil TK. Outbreak of aggressions and transmission of rabies in human beings by vampire bats in northeastern Brazil. Rev Soc Bras Med Trop. 2002;35(5):461-4.

18. Gupta R. Recent outbreak of rabies infections in Brazil transmitted by vampire bats. Euro Surveill. 2005;10(11):E051110.3.

19. da Rosa ES, Kotait I, Barbosa TF, Carrieri ML, Brandão PE, Pinheiro AS, Begot AL, Wada MY, de Oliveira RC, Grisard EC, Ferreira M, Lima RJ, Montebello L, Medeiros DB, Sousa RC, Bensabath G, Carmo EH, Vasconcelos PF. Bat-transmitted human rabies outbreaks, Brazilian Amazon. Emerg Infect Dis. 2006;12(8):1197-202.

20. McQueen JL, Lewis AL, Schneider NJ. Rabies diagnosis by fluorescent antibody. Its evaluation in a public health laboratory. Am J Public Health. 1960; 50: 1743-52.

21. Meslin FX, Kaplan MM , Koprowski H . The mouse inoculation test (Chapter 6), The fluorescent antibody test (Chapter 7). In: World Health Organization eds. Laboratory Techniques in Rabies. (Fourth Edition), Geneva; 1996.

22. Rodríguez G. Diagnóstico inmunológico del virus de la rabia en tejido incluido en parafina. Inf Quinc Epidemiol Nac. 1997; 16: 235-6.

23. Koprowski H. Prueba de inoculación en ratones. In: Organización Mundial de la Salud. Técnicas de Laboratorio aplicadas a la rabia. Washington D.C.: OPS/OMS; 1956. Pp. 57-69.

24. Dietzschold B, Rupprecht CE, Tollis M, Lafon M, Mattel J, Wiktor TJ, et al. Antigenic diversity of the glycoprotein and nucleocapsid proteins of rabies and rabies related viruses: implications for epidemiology and control of rabies. Rev Infect Dis. 1988; 10(Suppl. 4): 785-98.

25. Ministerio de Salud de Colombia, Instituto Nacional de Salud de Colombia. Rabia. Guía práctica para la atención integral de personas agredidas por un animal potencialmente transmisor de rabia. Serie de notas e informes técnicos No.4. 6th ed. Bogotá D.C.: MS-INS; 2002.

26. Lord RD. Guía sobre estrategia ecológica para controlar la rabia bovina. Ciencia Veterinaria. 1981; 3: 78-101.

27. Díaz A.M, Papo S, Rodriguez A, Smith J.S. Antigenic analysis of rabies virus samples from Latin America and the Caribbean. Zentralbl Veterinarmed B. 1994; 41(3): 153-60.

28. Greenhall AM. Feeding behavior. In: Greenhall AM, Schmidt U (eds) Natural history of vampire bats. CRC Press, Florida; 1988. pp. 111-31 
29. Baer GM. Vampire bat and bovine paralytic rabies. In Baer GM (ed) The Natural History of Rabies, $2^{\text {nd }}$ edition. CRC Press, Boston, Cap. 20; 1991.

30. Fundação Nacional da Saúde. Morcegos em áreas urbanas e rurais: Manual de Manejo e Controle. Ministério da Saúde. Brasília; 1996.

31. Lopez RA, Miranda PP, Tejada VE, Fishbein DB. Outbreak of human rabies in the Peruvian jungle. Lancet 1992; 339: 408-12.

32. Gonçalves MA, Neto RJ, Brazil TK. Outbreak of aggressions and transmission of rabies in human beings by vampire bats in northeastern Brazil. Rev Soc Bras Med Trop 2002; 35: 461-4.

33. Schneider MC, Santos-Burgoa C. Algunas consideraciones sobre la rabia humana transmitida por murciélagos. Salud Pública de México 1995; 37: 354-62.

34. Suescún O. Rabia en Antioquia, 1988. Boletín Epidemiológico de Antioquia 1988; 14 (1,2): $62-5$. 35. Páez A, Velasco-Villa A, Rey G, Rupprecht C. Molecular epidemiology of rabies in Colombia 19942005 based on partial Nucleoprotein gene sequences. Virus Res. 2007; 130: 172-81.

36. Páez A, Saad C, Núñez C, Bóshell J. Molecular epidemiology of rabies in northern Colombia 19942003: Evidence for human and fox rabies associated with dogs. Epidemiol Infect. 2005; 133: 529-36. 